University of Windsor

Scholarship at UWindsor

OSSA Conference Archive

OSSA 8

Jun 3rd, 9:00 AM - Jun 6th, 5:00 PM

\title{
A Self-Defeat Problem for the Rhetorical Theory of Argument
}

Scott F. Aikin

Vanderbilt University

Follow this and additional works at: https://scholar.uwindsor.ca/ossaarchive

Part of the Philosophy Commons

Aikin, Scott F., "A Self-Defeat Problem for the Rhetorical Theory of Argument" (2009). OSSA Conference Archive. 3.

https://scholar.uwindsor.ca/ossaarchive/OSSA8/papersandcommentaries/3

This Paper is brought to you for free and open access by the Conferences and Conference Proceedings at Scholarship at UWindsor. It has been accepted for inclusion in OSSA Conference Archive by an authorized conference organizer of Scholarship at UWindsor. For more information, please contact scholarship@uwindsor.ca. 


\title{
A Self-Defeat Problem for the Rhetorical Theory of Argument
}

\author{
SCOTT F. AIKIN \\ Philosophy Department \\ Vanderbilt University \\ 111 Furman Hall \\ Nashville, TN 37240 \\ USA \\ scott.f.aikin@vanderbilt.edu
}

\begin{abstract}
The rhetorical theory of argument, if held as the conclusion of an argument, is self-defeating. There are two arguments that it is. First is the quick and dirty argument: the rhetorical theory is that argument quality is adjudged by eliciting conviction, but the case for the theory is not convincing. Second is the process argument: if one has the view that one's reasons are arranged with the sole purpose of eliciting assent, one does not view one's resultant commitments as reflective of truth.
\end{abstract}

KEYWORDS: Crosswhite, Perelman, performative contradiction, rhetoric, Rowland, self-defeat, Tindale

\section{THE RHETORICAL THEORY OF ARGUMENT}

The rhetorical theory of argument is the view that the norms of argumentation derive from the practice of eliciting assent from audiences. On the rhetorical theory, arguments are speech acts performed for the sake of addressing some conflict or alleviating a concern, and their quality should be measured according to how effectively they achieve these ends. The theory has been expressed as follows: ${ }^{1}$

Perelman and Olbrechts-Tyteca: The goal of all argumentation [...] is to create or increase adherence of minds to the theses presented for their assent (1969, p. 45).

Wenzel: [F]rom the standpoint of rhetoric, a good argument is an effective one (1980, p. 120)

Crosswhite: [T] he aim of argumentation is to gain the adherence of other people [...] The merit of an argument can be determined by knowing the quality of the audience which would assent to it. Thus, a rhetoric of reason calls for a reception theory of rationality. (1996, p. 36)

Tindale: [A]rguments are judged successful and evaluated not directly in terms of their internal logical support, but in terms of their impact on the audience. The aim of argumentation is the adherence to its theses. It will be judged strong or weak according to the degrees to which this is accomplished. (1999, pp. 85-6)

\footnotetext{
1 "The aim of argumentation is not to deduce consequences from given premises; it is rather to elicit or increase adherence of the members of an audience to theses presented for their consent.” (Perelman 1982, 9) For further statements of the rhetorical theory, see: Johnstone 1952, p. 489; Burke 1984, p. 22; Sillence and Minors 1991; p. 290, Gross 2000, p. 319; and Schollmeier 2002, p. 386.
}

Aikin, S. F. (2009). A Self-Defeat Problem for the Rhetorical Theory of Argument. In: J. Ritola (Ed.), Argument Cultures: Proceedings of OSSA 09, CD-ROM (pp. 1-10), Windsor, ON: OSSA.

Copyright (C) 2009, the author. 
The general case for the rhetorical theory runs that, on the one hand, traditional theories fail to produce satisfying interpretive schemata and evaluative standards for arguments. Viewing arguments solely as logical products skews their evaluation. On the other hand, rhetorical theories, in their take on processes of argumentation, provide modes for interpretation of arguments as instruments and criteria for evaluation in terms of their effectiveness. Another appeal of the rhetorical theory is that there are no standards invisible to arguers - no need to point to formal logical truths or procedural rules with which arguers at best may be tacitly familiar. ${ }^{2}$ There are only arguers, the things they say and how they say them, audiences, and their assent or denial. Other motives for the theory are its purported ethical import of respect for interlocutors ${ }^{3}$ and the fact that it makes argument something worthy and attractive ${ }^{4}$. Importantly, my self-defeat argument is limited only to what might be called the strong program in the rhetorical theory of argument, namely, that all forms of argument are primarily rhetorical. Christopher Tindale captures the strong program by claiming that all argumentative standards, even logical standards, are audience-dependent, "the rhetorical is the vehicle for the development of the logical, for the logical is a product of audience and can be nothing more, nor less" (2004, p. 143). Perelman similarly holds, “all argumentation is rhetorical” (1965, p. 168). Contrast the strong program with modest programs that acknowledge separate spheres of evaluation, rhetoric being one among many other independent schema for evaluation (dialectical, epistemological, logical, and so on). I will mean only the strong program by 'rhetorical theory of argument.'

The central commitment of the rhetorical theory is the instrumental view on arguments and the processes of argumentation - that they are means to ends, and instruments and techniques are to be adjudged according to that criterion. ${ }^{5}$ This thesis is a two-part commitment, one descriptive account of what arguments are and a normative view as to how arguments are to be evaluated:

R1: Arguments are speech acts performed for the sake of eliciting assent or increasing commitment in an addressed audience.

R2: Arguments are to be assessed according to their effectiveness in eliciting the assent or increasing the commitment sought in their addressed audience.

The first thing to note is that R1 does not entail R2: the purposes of actions do not always mean they evaluated only in terms of whether they are successful. ${ }^{6}$ The case for their

\footnotetext{
${ }^{2}$ Versions of this argument are made by Hamblin 1970, p. 241; Crosswhite 1996, p. 161; and Heysse 1997, p. 220.

${ }^{3}$ Crosswhite 1996, p. 154; Tindale 1999, pp. 188-90.

${ }^{4}$ Crosswhite 1996, p. 135.

5 Scholmeier notes this connection between the rhetorical theory and pragmatism as forms of instrumentalism not only of the products of argument but the processes 2002, p. 389.

${ }^{6}$ For example, lies are speech acts performed for the sake of eliciting beliefs and actions that the speaker takes as false or misdirected. But surely we have criteria for evaluating lies beyond whether they achieve their ends - a lie's effectiveness has no direct bearing on whether it is good or just. What agents and cognizers are trying to accomplish with their actions surely is relevant to our normative assessments, but their effectiveness would only be part of such assessments. More on this issue in the coming pages.
} 
tighter connection in the case of the rhetorical theory, however, is along interpretive lines. The argument runs that arguments cannot be evaluated without interpretations of what the case made is, and this requires we consider the speaker's goals in addressing her audience and how the audience experiences the speaker's case. This requires a knowledge of the argument's context, what divides the speaker from the audience (the issue), and how the audience responds to the argument. Tindale notes that a desideratum of a theory of argument is that it provide "the most complete and satisfying account of what argumentation is, of what it is like to be engaged in argumentation, to be argued to, and to evaluate arguments” (1999, p. 7). The phenomenological perspective on argument yields the norms for evaluation that allow us to see the norms at work in the acts of arguers and their audiences.

Though the rhetorical theory of argument is about arguments and argumentation as performative instrumental processes, the theory itself is a theory, a proposition about arguments. Given that other theories of argument are rejected for some reasons and there are reasons that support the rhetorical theory, let us see the final case for the rhetorical theory of argument as a product of argumentation-as an argument for the truth of R1 and R2. Once we have taken this product-turn on the rhetorical theory, the troubles begin.

\section{THE QUICK AND DIRTY ARGUMENT}

The two commitments of the rhetorical theory, R1 and R2, are held on the basis of arguments. R1 and R2 are tied together-once we take the perspective of those engaged in the process of argument, the goals of argumentative speech acts and the norms of their evaluation are tied. Further, the theory is that R1 and R2 are true of arguments. Consequently, we must ask: if R1 and R2 are true of arguments, how well do the arguments for them live up to the standards set for them?

If R1 and R2 are true of argument, I would not have any reason to accept the arguments in favour of them. The following is an account as to how that is so. There are two ways we can see this. First is the quick and dirty way, and second is the process way.

The quick and dirty way is as follows. I've been exposed to the arguments for the rhetorical theory, and they did not convince me. So, by R2, they must not be very good arguments. I don't call it the quick and dirty argument for nothing.

Further, imagine a rhetorical theorist objecting to the quickness and dirtiness of the argument along these lines:

That doesn't count against the theory, because you've overlooked some important point or datum.

But note now the defence of the theory is very different from the theory: isn't it the rhetor's job to address the audience? Moreover, this defence requires that there are justifying elements to arguments that must obtain independently of audience assessment or acceptance, ones that, presumably, audiences are obliged to attend to if they are to be reasonable interlocutors. But this isn't the rhetorical theory anymore-arguments can be good arguments independently of audience-acceptance. But there is a further defence for the rhetorical theory here. R2 runs that we evaluate arguments according to acceptance by an audience, not any audience-arguments are addressed to specific audiences at specific 
times, and it is excessive to demand that they be right for anyone who happens to pick up the book. And they weren't tailoring their arguments for me. So the answer is, basically: We weren't talking to you. ${ }^{7}$ To his credit, James Crosswhite notes explicitly that his work is "addressed primarily to an audience concerned with the teaching of composition, secondarily to philosophers, teachers of critical thinking, composition theorists and educational administrators and policy makers” (1996, p. 3). He then argues that the rhetorical theory itself is not a description of the "necessary a priori features of all reasoning," but rather "an account which is better for particular purposes, and more convincing in the context in which it is offered, than are competing accounts" (1996, p. 16). Fair enough, but, I teach writing, am a philosopher, teach critical thinking, and have been a consultant for humanities curricula. I am a member of Crosswhite's primary and secondary audience. Perelman, too, takes what he's doing is philosophy, and hence must address a universal audience (1982, p. 17), which is "thought of as including all men who are rational and competent with respect to the issues that are being debated" (1968a, p. 21). Unless my membership card is expired, I think I belong to that class. And so the quick and dirty argument gets it done.

\section{THE PROCESS ARGUMENT}

The quick and dirty argument may be both too quick and too dirty in ways that invalidate it. Surely one thing it fails to accomplish is respect the processive element of argumentation that the rhetorical theory emphasizes. Something from the perspective of someone who is convinced by the theory may be necessary. What is called for is what I call a process version of the argument. It starts with the, I think plausible, observation that there is a distance between seeing oneself as being convinced of some proposition and taking that proposition as true. That is, we may often express our commitment to a view, but also express the distance between our commitment and its truth. Our usual attitudes of commitment are transparent, in that if you're committed to some content $p$, you're committed to its truth. When we are convinced of our beliefs' truth, we just assert them unvarnished: we just say "p." It's raining. My foot hurts. You're late. But there are cases where expressions of commitment can be peeled apart from commitments to truths. For example, when we do not know that something is true, but nevertheless find ourselves committed, we say:

\section{(1) I believe that p.}

We express our assent to p, but it seems, also withhold our commitment to its truth. ${ }^{8}$ In the same way, we can capture this distance between commitment and truth in the third person:

\footnotetext{
${ }^{7}$ If this defense sounds implausible and uncharitable, it is. But it has been given, but (lucky for the ones giving the defense) under anonymity of review: "[A] rhetorical theorist, having accepted the pragmatist assumptions of his/her approach, rejects [the argument] and so is not concerned by this alleged refutation." And, "[R]hetorical theory is just assumed to fit neatly into a philosophical framework from which it has recently self-consciously separated itself."

${ }^{8}$ See my 2006 for an extended analysis of contrastively attributing beliefs to oneself.
} 
(2) He believes that p.

The point here is that we can recognize some arguments as ones that elicit our assent, but eliciting our assent is one thing and convincing us that what we assent to is true is something else. It is a qualified or very weak endorsement of an argument to say that one was convinced by it. But it is something else to assess the argument as giving one a reason to believe the truth of its conclusion. The fact that one believes its conclusion, it seems is, again, only a qualified commitment to its truth, as we saw with 1, above. For example (and this may be a bit too autobiographical, but here goes) I found myself convinced by almost everything Bill Clinton said, but I would hardly say that what I was convinced of was true. This has not yet said anything about the argument or its quality. One can say of arguments that they convinced some third party, but are bad arguments:

(3) He was convinced by argument (A) to accept p, but A is a bad argument for p.

Additionally, one can even say this of oneself, so that one can concede that the argument was successful in eliciting assent, but was a bad argument. We express argumentative regret:

(4) I was convinced by A to accept p, but A is a bad argument for p.

On top of this, it seems that the speaker in either case can be qualifiedly convinced (as in 1 , above) of the conclusion and yet utter either of these statements. These are cases where speakers can recognize their own intellectual shortcomings, that, perhaps, they are suckers for certain tropes or the manners of some speaker. (Again, imagine someone like myself, who's a fool for Clinton-isms.) They express their commitments, but do not fully commit to a truth. With these cases, one takes a third-personal view on one's own beliefs and takes there to be a distance between one's qualified assent and the truth of what is assented to.

This said, if we have what might be called unqualified assent from the first person perspective (ones where one's commitments are transparent and we assert unvarnished "p"), we have the commitment to the truth and the commitment to a proposition tied closely. Statements like (1) and (4) are out of bounds. Further, one cannot, without thereby qualifying or weakening the commitment, utter statements like:

(5) I hold that p is true, but for reasons that have nothing directly to do with p's truth.

(6) I hold that $\mathrm{p}$ is true on the basis of an argument devised only to elicit my assent to $\mathrm{p}$.

For there to be a tight connection between assessing oneself to be committed to a proposition and holding that proposition true, one must take oneself to hold the commitment on the basis of reasons indicative of that proposition's truth, not reasons designed to elicit assent. That is, unqualified assent is reality-centered-it's about the facts, and one holds one's commitment to be fact-based. Qualified assent is subjectcentered-it is not about the facts, but about the speaker, and one holds one's 
commitment to be based on her own inclinations, beliefs, and unique standards. Statements 5 and 6 qualify the commitment, and this can be seen in the similarity of the following:

(7) He holds that p is true, but for reasons that have nothing directly to do with p's truth.

(8) He holds that p on the basis of an argument devised only to elicit his assent to p.

In 8, we see that the third person's assent to the premises of the argument has nothing directly to do with p's truth. But it is about that third person (what to expect from him or her, some history that brought about the belief, and so on). The thought generalizes just as statement 2 does to yield the equivalent qualification in 1, so that 6 is a qualified commitment to p, not an unqualified commitment.

Now let us apply these lessons to the rhetorical theory of argument. R1 and R2 are supported by arguments (A1, A2, .., An), and so those that hold they are true presumably hold them on the basis of those arguments. They must hold the following:

(9) I hold R1 and R2 on the basis of A1, A2, .., An.

Perelman claims that "all argumentation is rhetorical" and the emphasized quantifier certainly extends this analysis to his own case for the rhetorical theory (1968b, p. 168). Since the rhetorical theory bears on the arguments that support it, the following is a consequence:

(10) R1 and R2 are true of A1, A2, .., An.

(11) A1, A2, ..., An are devised only to elicit my assent with regard to R1 and R2 and are to be evaluated according to how well they elicit my assent.

Once we have closed the implications of R1 and R2 with regard to A1, A2, .., An, we should yield the following:

(12) I hold R1 and R2 on the basis of arguments devised to elicit and to be evaluated only on the basis of my assent.

The problem is that 12, like 1 and 6 before, yields a statement of qualified assent, and not unqualified assent-one reports the beliefs and inclinations of a cognizer, not an endorsement of the truth of the views. If $\mathrm{R} 2$ is true, then the arguments must not be particularly good arguments, because the quality of an argument is determined by the degree of adherence. Since this is qualified assent, the argument must not be effective, and hence, on R2, is not a good argument. This reasoning then reduces 12 , instead of to 6 , but to 4 , which amounts to outright confession of intellectual failure. ${ }^{9}$

9 A related problem is that the reception theory of rationality behind R1 and R2 seems to impel evaluators of arguments to silence on features of arguments that would make them acceptable or not. They then face the following question:

Is argument A a good argument because you assent to it, or do you assent to A because it is good? 


\section{PERFORMATIVE CONTRADICTION REDUX?}

A version of this self-defeat argument has been made before, and rhetorical theorists have been aware of something along its lines for some time. Robert Rowland presents one such line of criticism, namely, that in order to critique traditional concepts of rationality, postmodernists must make use of the tools of rationality, specifically, arguments (1995). So there is a " 'performative contradiction' at the heart of postmodern critique," because postmodernists' cases must proceed on the basis of their "use (of) argument to attack argument" (p. 351). Because this is a critique, the postmoderns "claim that their positions are more defensible than those of their opponents" (p. 351). However, in making these arguments, they "recognize [...] the functional utility of general standards for testing argument form and process” (1995, 358). Jürgen Habermas's argument from 'performative contradiction' in his Philosophical Discourse on Modernity also takes a similar tack, as he notes that when one takes critique as rhetoric, one "dulls the sword of the critique of reason itself” (1987, p. 210).

This 'performative contradiction' line of argument is similar to mine here, but it is not identical. First, Rowland and Habermas's argument is taken as a defence of rational argument from the critique of postmoderns-namely, that because theorists X and Y (the usual suspects) use arguments in their critique of argument, they must tacitly rely on rational argument. This is not my argument. Instead, my argument is that if one is convinced by the case for rhetorical theory (it may not even be arguments, traditionally conceived), one will be progressively less and less convinced by the case when one views it again through the lenses of the theory. That the rhetorical theory is self-defeating is not yet the stronger vindication of rational argument we see in Rowland and Habermas. The failure of the strong program on my argument is logically distinct from (though certainly relevant to) the defence of rational argument.

A second difference between my argument here and the Habermas-Rowland performative contradiction argument is that theirs proceeds from the perspective of the conditions for argument. Though I am sympathetic with that method, I am not employing it here. My method, instead of what must precede arguments, is from what follows from the arguments for the strong program of rhetoric. The only assumptions here are that the pragmatic force of saying that one believes a proposition weakens one's expressed commitment to its truth and that when one sees a case as addressed expressly to you instead of about the facts, there is a correlate weakening of commitment, even if the case yields assent. These are not the transcendental inferences at work in the RowlandHabermas arguments, but rather observations about how self-ascribed commitment works. Nevertheless, a defence of my argument here against some challenges to the

If the good-making property of an argument is the former, then it seems that evaluators should explain the badness of an argument in terms of their rejection of it, which is precisely how 12 reduces to 4 . But this gets the phenomenology of responsible argument evaluation backwards. Surely if someone has directed an argument to us in order to change our minds, we would evaluate the argument as good only on the conditions that it gives us a better position on the issue, one that allows us a better command of the fact, one that fits with the evidence. Conceding that an argument made you unqualifiedly change your mind means that you've overcome your inclination to reject the conclusion by way of your attentiveness to something in the argument beyond your inclination to assent. You get over yourself and you attend to the facts. 
Habermas-Rowland line of argument is worthwhile, if only because it seems widely taken that rhetoric's strong program can answer the performative contradiction argument.

I do not have space to address the postmodern responses to Habermas, but Christopher Tindale has responded to Rowland's argument in a manner that can focus discussion. His rebuttal runs as follows (I have numbered the distinct arguments for reference):

[W] hile this raises interesting questions, such as (i) how the history of Reason can contain the conditions that give rise to its own critique, (ii) it fails to engage the debate in a useful manner, it fails to meet the critics where they stand. Besides, (iii) there may be no inconsistency in using argument to show that it does not have the value attributed to it (Tindale 1999, p. 188).

Given the general similarity between Rowland's argument and mine, I will take these rebuttals as relevant to my project, too (and leave Rowland's responses to Rowland). Tindale's (i) is that the 'history of Reason' (note the capital R) can give rise to its own critique. But the pronoun reference is unclear-is the critique of Reason or of its history? It's likely the former, and so the thought would be that the activities of Reason over time provide evidence for criticisms of Reason. This seems plausible, but only if one takes the norms of Reason to be coordinate with that of the functioning of human minds. But that coordination strips the norms of Reason (with a big $\mathrm{R}$, which implicates something like timeless Platonic forms) of their status as normative in the sense that gives them purchase. Surely a defender of Reason so construed would say such an identification begs the question (they are timeless forms, you know) - that people make use of and fall for fallacies regularly is not evidence against norms of reasoning, and certainly does not bear in any way on the norms of Reason. Tindale's (iii) speaks directly to this, in that given our limitations, perhaps the critique of Reason may not be in terms of it achieving standards it sets for itself. Instead, it may be in the conflict between standards that are too high and the beings upon which they bear-norms that are too demanding may be irrelevant. But notice that if the case made is that we cannot meet these standards and so we should forego them itself is considerably weaker than these standards (as the rhetorical theory must hold that it is), then where does that leave us? Again, rhetorically successful arguments are addressed to audiences with certain kinds of commitments, and in this case, it must be the commitment to Reason that must function as the criterion. (You don't have to give arguments to give up Reason to those who've already done it.) If that's the case, then the arguments that do not live up to the audience's standards will not move them, and this is not the audience's fault on the rhetorical theory, but the fault of the rhetor and her case. As a consequence, the case for the rhetorical theory against Reason, to live up to its own standards of being rhetorically successful, is hopeless.

Tindale's rebuttal in (ii) runs that the Rowland argument fails to engage the debate, because it fails meet the critics of Reason where they stand. This is right in one way-the Habermas-Rowland argument proceeds in both cases from theories of argument, a transcendental pragmatics in Habermas's case and a cognitive pragmatism in Rowland's. And so, both import some theoretical apparatus to then criticize their opponents. That is a legitimate problem, but Tindale says there is no useful consequence of this. This overstates the case, because at issue are the norms of argumentation. Nothing useful may come of it if the rhetorical theory is the standard for what's worthwhile coming from an argument-roughly that an argument achieves something useful only if it 
meets its audience where it lives. But this presumes that the rhetorical theory is right. Why else would Tindale require that critics of the rhetorical theory live up to the rhetorical theory's standards? But does the requirement that the critics of rhetoric meet those they criticize where they live itself meet those critics of rhetoric where they live? If the requirement is that if you're going to criticize a theory of argument or any of their cases, you have to meet them where they live, then does that requirement work when applied to criticize those who reject the requirement? I think not, because I reject the rhetorical theory of argument. Again, the points that Tindale scores against Rowland and Habermas are on the basis of the fact that they import their theories of argument to criticize the rhetorical theory-but this case goes through only if one imports the rhetorical theory for its own defence. Regardless, the objection doesn't have to bear on my version of the self defeat argument, because I concede at the front end of the process version that R1 and R2 are true, and then from the (I suppose) uncontroversial observations that belief-embedding qualifies commitment, the result follows. My version runs internal to the perspective of someone convinced of the rhetorical theory. So even if Tindale's (ii) is right about Rowland (though I'm not convinced it is), the process selfdefeat argument is still unscathed.

ACKNOWLEDGEMENTS: Thanks to James Bednar, Andy Cling, Allen Coates, Michael Harbour, John Hardwig, Nick Jones, Jonathan Neufeld, Brian Ribeiro, Robert B. Talisse, and Jeffrey Tlumak for comments on and discussions regarding this paper.

\section{Link to commentary}

\section{REFERENCES}

Aikin, S. (2006). Contrastive self-attribution of belief. Social Epistemology 20, 93-104.

Aikin, S. (2008a). Perelmanian universal audience and the epistemic aspirations of argument. Philosophy and Rhetoric 41, 238-59.

Aikin, S. (2008b). Holding one's own. Argumentation 22, 571-84.

Burke, R. (1984). A rhetorical conception of rationality. Informal Logic 6, 17-25.

Crosswhite, J. (1996). The Rhetoric of Reason. Madison: University of Wisconsin Press.

Gross, A. (2000). Rhetoric as a technique and a mode of truth: Reflections on Chaïm Perelman. Philosophy and Rhetoric 33, 319-334.

Habermas, J. (1987). The Philosophical Discourse of Modernity. Frederick Lawrence (trans.), Cambridge: Cambridge University Press.

Hamblin, C.L. (1970). Fallacies. London: Methuen

Heysse, T. (1997). Why logic doesn't matter in the (philosophical) study of argumentation. Argumentation $11,211-224$.

Johnstone, H. (1952). Philosophy and argumentum ad hominem. The Journal of Philosophy 49, 489-98.

Perelman, C. and Olbrechts-Tyteca, L. (1969). The New Rhetoric. Trans. J. Wilkinson and P. Weaver. Notre Dame: University of Notre Dame Press.

Perelman, C. (1968a). Rhetoric and philosophy. Philosophy and Rhetoric 1, 15-24.

Perelman, C. (1968b). Reply to Mr. Zaner. Philosophy and Rhetoric 1, 168-70

Perelman, C. (1982). The Realm of Rhetoric. Trans. W. Kluback. Notre Dame: University of Notre Dame Press.

Rowland, M. (1995). In defense of rational argument: A pragmatic justification of argumentation theory and Response to Postmodern Critics. Philosophy and Rhetoric 28, 350-64.

Schollmeier, P. (2002). Pragmatic method and its rhetorical lineage. Philosophy and Rhetoric 35, 386-391.

Sillence, J.A.A. and R. H. Minors (1991). What makes a strong argument? Emotions, highly placed values, and role-playing. Communication and Cognition 24, 281-298. 


\section{SCOTT F. AIKIN}

Tindale, C. (1999). Acts of Arguing. Albany: SUNY Press.

Tindale, C. (2004). Rhetorical Argumentation. Thousand Oaks, CA: Sage Publications.

Wenzel, J.W. (1980) Perspectives on argument. In: J. Rhoeds \& S. E. Newell (Eds.) Dimensions of Argument: Proceedings of the summer conference on argumentation. (pp. 112-133) Annandale, VA: Speech Communication Association. 